॥llii.|॥

UNIVERSITÉ DU

LUXEMBOURG

\title{
German University-based Science: From Model to Contemporary Reality?
}

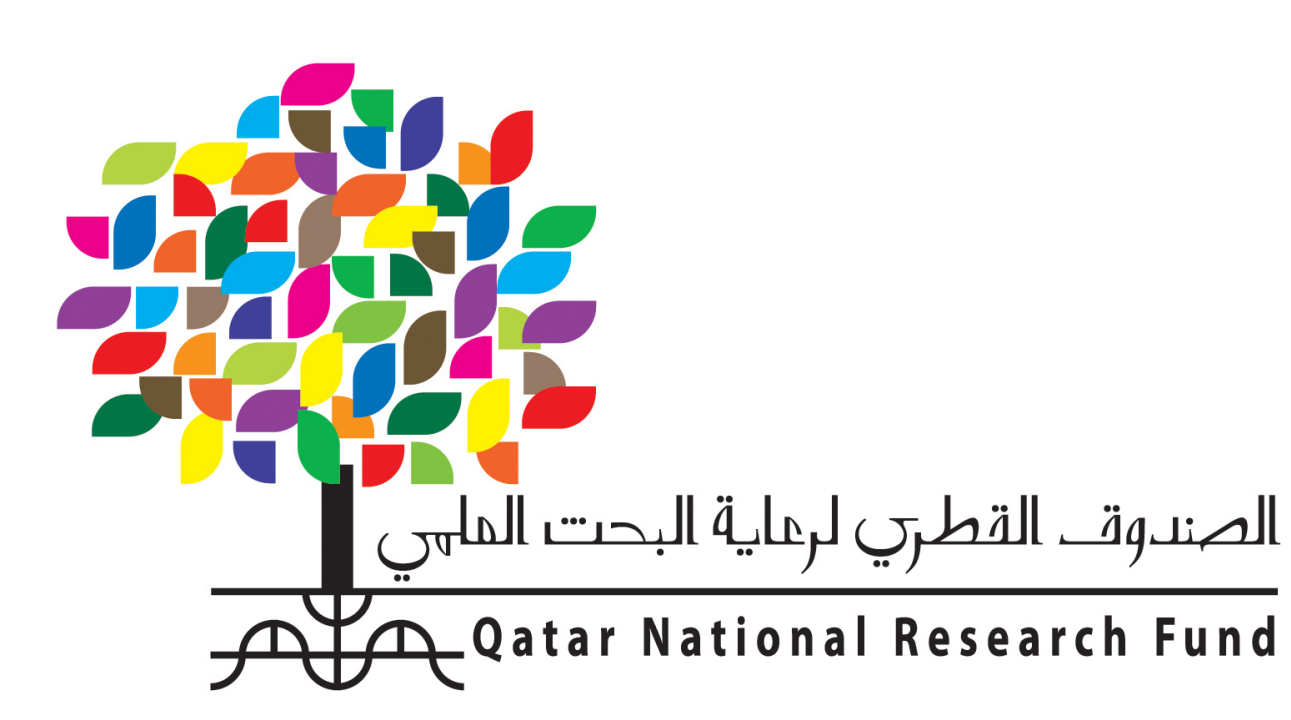

Member of Qatar Foundation

\section{Introduction}

- The enormous potential of a knowledge society depends on continued production of scientific knowledge, but also its specification and enhanced quality.

- While global production has grown substantially, a few nations still produce the overwhelming majority of new science (see fig. 1).

- Our preliminary research suggests that differences in key aspects of institutional models of higher education development and science capacity-building are associated with cross-national differences in scientific knowledge production over time.

- Scientific publications (especially journal publications) are the fundamental way of allocating and ascribing reputation.

\section{Project description}

Science Productivity, Higher Education Development, and the Knowledge Society: China, Germany, Japan, Taiwan, Qatar, United States (NPRP No.: 5-1021-5-159) funded by the QNRF (2012-2014)

This project is a cross-national investigation of the influence of higher education development and science capacity-building on scientific knowledge production. Measuring science on the basis of published papers in selected STEM disciplines, we identify factors behind national differences and global similarities. How does variation in national models and strategies to develop higher education and research universities explain different long-term national trajectories in science productivity since 1900? Observing unprecedented growth in scientific knowledge productivity, we selected six cases that represent different phases of higher education development and sciencebased societies: a major European precursor model (Germany's "Humboldtian" research university), broad institutionalization of the currently dominant model (American "super research university"), and a range of innovators in Asia (Japan, China, Taiwan) and the Middle East (Qatar).

The German "Humboldtian" university model

Preeminence in modern science since $19^{\text {th }}$ century into the $20^{\text {th }}$

\section{Characteristics: Freedom to teach and to study, autonomy of and itment to science, monopoly on granting doctoral degrees}

Foundational principle of a research
university: nexus of research and teaching

Equipped with enormous prestige and receiving sustained attention worldwide
Rise of extra-university research institutes in Germany

Massive educational expansion in the 1960s

Characteristics: Well-resourced, cutting-edge facilities, limited teaching duties

Determined by federal interdependence, as both the Feder and Länder governments jointly provide the funds for these institution

International collaborations were animated by major research ssociations (HGF, MPG, WGL, FhG)

\section{Research question}

To what extent is higher education development in Germany a model for expanding higher education systems in other countries?

\section{Hypotheses}

$\mathrm{H1}$ : The foundational principle of the modern research university, established in Germany, is the nexus of research and teaching

H2: Massive tertiary educational expansion over the post WWII period, the rise of extra-university research institutes, and establishment of praxis-oriented universities of applied sciences challenge the foundational principle.

H3: Today, the dual structuring of German science - research universities and specialized extrauniversity research institutes - affects research capacity and may threaten this globally popular model.

\section{Data and methods}

Qualitative study: Historical study of each nation's model of university-based science of higher education development, and of science capacity-building - and comparison of these.

Quantitative study: Stratified representative sample of published papers in journals in science and technology disciplines, relying on a unique raw dataset from Thomson Reuters' Web of Science $(1900-2010)$

\section{Conclusion}

Germany successfully exported its educational model - the research university - worldwide. With substantial research capacity, the German "Humboldtian" university model inspired the American. The super research university is an achievement that takes the German model one step further. To some extent, Education City in Doha has indirectly incorporated the German "Humboldtian" university model with the establishment of branch-campuses of American and European universities. 